\title{
Do animals satiate or habituate to repeatedly presented reinforcers?
}

\author{
FRANCES K. MCSWEENEY \\ Washington State University, Pullman, Washington \\ and \\ JOHN M. ROLL \\ Wayne State University, Detroit, Michigan
}

\begin{abstract}
Operant response rates may decrease within experimental sessions. The most likely explanation for the decrease is that satiation or habituation reduces the effectiveness of the repeatedly presented reinforcer. We argue that, contrary to intuition, both empirical and formal arguments favor habituation over satiation. Attributing the decreases in operant responding partly to habituation challenges the traditional assumption that habituation alters only reflexive behavior and does not occur to biologically significant stimuli. It preserves common terminology during operant and classical conditioning and when appetitive and aversive stimuli are used. It may provide a relatively general description of temporal changes in behavior in a wide variety of situations and may help to integrate motivational variables into theories of conditioning.
\end{abstract}

Rate of responding may increase, decrease, or increase and then decrease during sessions of operant conditioning (see, e.g., McSweeney, Hinson, \& Cannon, 1996). Although these within-session changes have been reported in many studies from a number of different laboratories (McSweeney \& Roll, 1993), they have received little systematic study until recently (but see, e.g., Spear, 1973). Recent experiments have questioned explanations for the changes such as recovery from handling (McSweeney \& Johnson, 1994), anticipation of events that follow the session (McSweeney, Weatherly, \& Swindell, 1995), changes in a general motivational state (e.g., arousal, McSweeney, Swindell, \& Weatherly, 1996a, 1996c), changes in attention defined in two different ways (McSweeney, Roll, \& Weatherly, 1994; McSweeney, Weatherly, \& Swindell, 1996b), changes in factors produced by responding such as muscular warmup and fatigue (McSweeney, Weatherly, \& Roll, 1995; McSweeney, Weatherly, Roll, \& Swindell, 1995; Melville, Rybiski, \& Kamrani, 1996; Weatherly, McSweeney, \& Swindell, 1995), and changes in interference from exploration (Roll \& McSweeney, 1997) or adjunctive behaviors (McSweeney, Swindell, \& Weatherly, 1996a). Finding the early-session increases

This material is based on work supported by the National Science Foundation under Grants IBN-9207346 and IBN-9403719 to F.K.M. and by NIDA Grant T32DA07267 to J.M.R. The authors would like to thank Samantha Swindell and Jeffrey N. Weatherly for their help in conducting the experiment on dishabituation. They would also like to thank Alan Baron, Jeffrey N. Weatherly, and Cam L. Melville for their comments on an earlier version of this manuscript. Finally, they are indebted to Richard L. Shull for his suggestion of the Millenson reference. Correspondence should be addressed to F. K. McSweeney, Department of Psychology, Washington State University, Pullman, WA 99164-4820 (fkmcs@mail.wsu.edu). without the late-session decreases and vice versa also questions explanations in terms of yoked opponent processes (see, e.g., Solomon \& Corbit, 1974).

In contrast to these failed explanations, within-session changes in responding may be produced mainly by systematic changes in the "value" or effectiveness of the reinforcer across the session (McSweeney, Weatherly, \& Swindell, 1996a). ${ }^{1}$ The two most likely explanations for decreases in reinforcer effectiveness are that subjects satiate (Killeen, 1995) or habituate (McSweeney, Hinson, \& Cannon, 1996) to the reinforcer with its repeated presentation. In both cases, it must be assumed that reinforcers lose their ability to support instrumental responding as subjects satiate or habituate to them.

The assumption that satiation produces the late-session decreases in responding is a widely and strongly held opinion among operant researchers (e.g., Killeen, 1995). We argue here that, contrary to intuition, habituation provides a better explanation than satiation, at least under the moderate conditions (i.e., intermediate rates of reinforcement) used in most studies. That is, to date, using an understanding of satiation to make predictions about within-session patterns of operant responding has yielded incorrect results. Using an understanding of habituation has yielded correct results.

We begin by defining habituation and satiation. We discuss arguments that favor each of these explanations. Finally, we discuss some theoretical implications of attributing within-session decreases in responding to habituation.

\section{DEFINITIONS}

A vast literature examines satiation. Experiments in this literature determine the factors that contribute to the 
termination of consumption of ingestive stimuli such as food and water. The factors that contribute to termination are called satiety factors. A similarly large literature examines habituation. These experiments study the behavior that results when a stimulus is presented repeatedly. In spite of the large literatures on these topics, there is no universally accepted definition of satiation or habituation (see, e.g., Savory, 1988).

We believe that the following definitions are compatible with the way in which satiation and habituation are usually used and are useful in understanding withinsession changes in operant responding. We define satiation as a decrease in the consumption of an ingestive stimulus (see, e.g., food, water) as that stimulus is repeatedly consumed. We define habituation as a decrease in responsiveness to a stimulus when that stimulus is presented repeatedly or for a prolonged time (see, e.g., Groves \& Thompson, 1970). Because reinforcers are stimuli, habituation might occur when they are repeatedly presented.

We have defined satiation and habituation by an operation (repeated presentation of a stimulus for habituation, consumption of an ingestive stimulus for satiation) and its effect on behavior (responsiveness to the stimulus decreases for habituation, consumption of the stimulus decreases for satiation). Therefore, our definitions are similar to the definition of reinforcement as an increase in responding (an effect on behavior) that occurs when a reinforcer follows that response (an operation). We do not define the concepts in terms of internal states, although they undoubtedly have a physiological basis.

We reject several other definitions of satiation and habituation. Occasionally satiation is defined as the loss of power to reinforce as a result of repeated presentation of a reinforcer (e.g., Millenson, 1967, p. 367). If that definition is adopted, then late-session decreases in operant responding are produced by satiation. We avoid this definition for several reasons. First, it restricts the term $s a$ tiation to operant conditioning (i.e., to cases in which the stimulus is a reinforcer and the reinforcer loses its effectiveness). Without further tests, the term could not be used to describe the termination of eating, probably its most frequent usage. Second, the definition may be inappropriate when noningestive reinforcers are used. For example, it seems unlikely that response rates decrease late in sessions of negative reinforcement (see, e.g., Jerome, Moody, Connor, \& Ryan, 1958) because subjects satiate to the termination of an aversive stimulus. Finally, nothing would be learned from this definition. The late-session decreases in operant responding would be labeled "satiation" without specification of which aspect of reinforcer presentation (e.g., changes in stomach distension, blood glucose levels, etc.) produced the loss of reinforcer value. Therefore, this definition would discourage, rather than facilitate, research.

Habituation is sometimes assumed to reduce "elicited" or "reflexive," but not "emitted" or "voluntary" behavior, such as operant responding (see, e.g., Catania, 1979, p. 52). Consistent with this idea, physiological studies of habituation usually do employ reflexive preparations such as gill withdrawal in Aplysia. However, other considerations argue against this restriction of the term. Behavioral studies often investigate complicated behaviors such as length of visual fixation, aggression, sexual responsiveness, song, or exploration (see McSweeney, Hinson, \& Cannon, 1996). Such behaviors are not clearly reflexive, although they may be elicited in some sense. The restriction is also inconsistent with some common uses of the term habituation. As will be argued, habituation is often offered as an explanation for changes in the ability of an unconditioned stimulus (US) to support classical conditioning (e.g., Randich \& LoLordo, 1979). It is not restricted solely to changes in the size of the unconditioned, reflexive, response (UR). Finally, this restriction ignores information about habituation. Variables located at the level of the central nervous system, not just at the reflex arc, contribute to habituation (see, e.g., Groves \& Thompson, 1970). Therefore, habituation could be expressed in a number of different behavioral measures and in complicated behaviors.

Habituation is sometimes assumed to occur to "neutral" but not to "biologically important" stimuli or to reinforcers (e.g., Thorpe, 1966, p. 74). Such a restriction may have arisen because habituation may fail when stimuli are strong (e.g., Groves \& Thompson, 1970) or when protective reflexes are investigated (e.g., Kimmel, 1973). However, habituation clearly does occur to stimuli that serve as positive reinforcers (e.g., food), and this habituation may play a role in limiting consumption (i.e., producing satiation). For example, in a series of experiments, Swithers, Hall, and their colleagues gave rat pups brief intraoral infusions of food (usually a sucrose solution, e.g., Swithers \& Hall, 1994). Responsiveness to food, measured by mouthing, increased and then decreased with repeated infusions. The decreases in mouthing were also accompanied by "satiety." That is, when the pups mouthed less, they also ingested less of the food when given the opportunity to consume it freely (SwithersMulvey \& Hall, 1992). This satiety was produced by changes in oral responsiveness to the food because postingestive consequences were minimized. The pups were too young to metabolize sucrose, and only small amounts of fluid were delivered, reducing gastric fill. The changes in oral responsiveness were probably produced by sensitization (increases in mouthing) and habituation (decreases in mouthing) to the food because they shared many of the empirical properties of sensitization-habituation to noningestive stimuli (Swithers \& Hall, 1994). Such data strongly challenge the idea that habituation does not occur to stimuli, such as food, that may serve as reinforcers.

As a final point, confusion arises between satiation and habituation because habituation to the sensory characteristics of ingestive stimuli (e.g., the taste) may contribute to satiation for those stimuli (e.g., Swithers-Mulvey \& Hall, 1993). Other factors that contribute to satiation include gastric fill, circulating levels of glucose, postingestive consequences, and the nutritional state of the animal. Because habituation is one of many factors that may contribute to satiation, the two terms make the same 
predictions in some cases. However, as will be argued, the terms also make substantially different predictions in several situations.

\section{ARGUMENTS FOR SATIATION}

Only a few data support the idea that satiation produces the late-session decreases in operant responding. In a thorough study, Palya and Walter (1997) investigated within-session changes in operant responding using several procedures and parameters. ${ }^{2}$ Although satiation and habituation provided similar predictions for most of their data, satiation seemed superior in two cases. First, response rate did not change systematically within sessions when pigeons were allowed to take only approximately one bite of food per reinforcer. The small amount of food given per reinforcer might prevent satiation and therefore prevent the late-session decreases in responding. Second, responding changed within sessions for small, but not for large, pigeons. This result is compatible with satiation if it is assumed that the same reinforcers produce more satiation for smaller than for larger subjects. In contrast, it is not obvious why the rate of habituation (i.e., the rate of change in responsiveness to the sensory properties of food) should vary with the subject's body weight.

Palya and Walter's (1997) evidence does not convincingly support satiation over habituation, however. To begin with, finding that within-session decreases in responding do not occur when subjects obtain only approximately one bite of food per reinforcer is as compatible with habituation as it is with satiation. The one-bite condition minimized exposure to the stimulus properties of the food. Therefore, less habituation might be expected than in conditions that allowed more lengthy exposure.

But also, finding that within-session changes occur for small, but not for large, birds shows only that the size of the subject was correlated with the size of the withinsession change in response rate. Correlational evidence should not be interpreted as causation. The data are open to many alternative interpretations in addition to the favored idea that smaller birds showed larger within-session changes because they were more satiated. For example, smaller birds may be smaller partly because they habituate quickly to the taste of food and therefore consume less. Faster habituation to food would also produce larger within-session changes in responding for the smaller pigeons when food was used as the reinforcer.

\section{EMPIRICAL ARGUMENTS THAT FAVOR HABITUATION OVER SATIATION}

\section{The Characteristics of Habituation and Within- Session Changes in Operant Responding Are Similar}

Several empirical arguments favor habituation over satiation. First, the characteristics of habituation and withinsession changes in responding are strikingly similar. Thompson and Spencer (1966) identified nine charac- teristics of habituation. Since 1966, some of these characteristics have been questioned (e.g., the effect of stimulus intensity, Groves \& Thompson, 1970); some are considered less important or of limited generality (e.g., habituation below zero, Wyers, Peeke, \& Herz, 1973); and others have been added to the list (e.g., sensitization, Groves \& Thompson, 1970; stimulus specificity, Swithers \& Hall, 1994). Nevertheless, the presence of habituation is usually established when behavior conforms to a series of empirical characteristics similar to those offered by Thompson and Spencer (e.g., Leaton \& Tighe, 1976; Teyler, Chiana, DiScenna, \& Roemer, 1984).

In keeping with this tradition, McSweeney, Hinson, and Cannon (1996) showed that many of the characteristics of habituation are also characteristics of within-session changes in operant responding. In both cases, the peak rate of responding is usually reached earlier in the session and the decline in responding is steeper when stimuli are presented at higher than at lower rates. Both changes in responding "spontaneously recover" over time. Both changes are altered by experience. In both cases, the form of the changes depends on the exact nature of the stimulus conditions. Both phenomena are produced by retrospective factors that accumulate over time rather than by anticipation of events to come. Neither change can be attributed to effector "fatigue." Both are general phenomena that occur for a wide variety of species performing a wide variety of responses. Finally, the basic form of the changes is similar. The changes are often bitonic, but the increases may occur without the decreases and vice versa. When all data are represented similarly, both changes can be described by the difference between a negative exponential decay function (habituation) and an ascending rectangular hyperbola (sensitization).

Since the time of that review, four more properties of habituation have been shown for within-session changes in operant responding. First, habituation may be faster and more pronounced for less, than for more, intense stimuli (Thompson \& Spencer, 1966; but see also Groves \& Thompson, 1970). Melville, Rue, Rybiski, and Weatherly (1997) varied the intensity of food by changing the concentration of a sucrose solution. They found steeper late-session decreases in operant responding when less, than when more, concentrated sucrose solutions served as the reinforcer. Such a finding is the opposite of the prediction of satiation. Consumption should terminate faster when higher than when lower concentrations of sucrose are given.

Second, habituation is relatively specific to the stimulus that is presented (i.e., stimulus specificity, e.g., Swithers \& Hall, 1994). Therefore, responding should change when the stimulus is changed. Rybiski (1996) demonstrated stimulus specificity for operant responding by altering the reinforcer from a sucrose solution to a food pellet at $10,20,30,40$, or $50 \mathrm{~min}$ into a 60 -min session in different conditions. Rate of responding increased after the change of reinforcer in all conditions (see also McSweeney, Swindell, \& Weatherly, 1996c; McSweeney, Weatherly, \& Swindell, 1996a). 
Third, because habituation is relatively specific to the delivered stimulus, making frequent changes in the stimulus slows habituation. Consistent with this finding, Melville et al. (1997) reported that within-session changes in operant responding were observed when subjects responded for grape-flavored liquid reinforcers throughout the session. Operant responding changed little within the session when grape reinforcers were sometimes replaced by one of three types of solid pellets. Venator, Boothe, and Hallford (1997) also reported that within-session changes in operant responding were flatter when reinforcer duration varied within a session than when duration was held constant.

Finally, we conducted the following experiment to demonstrate dishabituation - the recovery of habituated responding after the presentation of a strong, different, or extra stimulus (see, e.g., Groves \& Thompson, 1970). Four experimentally experienced pigeons, maintained at $85 \%$ of their free-feeding weights, pecked a key illuminated with white light. Pecking was reinforced by 5 -sec access to mixed grain. During baseline sessions, reinforcers were delivered according to a fixed interval (FI) 30sec schedule. Sessions were $60 \mathrm{~min}$ long, excluding the time of reinforcer delivery, and baseline was presented for 30 sessions, conducted daily five to six times per week.

Following baseline, an experimental phase was conducted consisting of several repetitions of five baseline sessions followed by a test session. During the test session, a dishabituating event was presented for 2 min starting at $40 \mathrm{~min}$ into the session. After this 2 -min period, the baseline, FI 30-sec schedule resumed. The dishabituating event was extinction, an FI 5-sec schedule, the availability of three reinforcers for the next three responses whenever a reinforcer was scheduled, or an increase in the length of the reinforcer to $20 \mathrm{sec}$. These dishabituating events were presented in different test sessions and the presented event was determined randomly at the beginning of the session. The combination of five baseline sessions and a test session was repeated until each of the dishabituating events had been presented five times. The test sessions were separated by baseline sessions to prevent subjects from habituating to the dishabituating stimulus (see, e.g., Thompson \& Spencer, 1966). All other procedural details were similar to those in baseline. When the experimental phase had been completed, baseline was repeated for 30 sessions.

We examined dishabituation by changing the reinforcer, rather than by introducing an additional stimulus (e.g., a loud noise) to separate the predictions of habituation and satiation. If satiation produces the late-session decreases in responding, then increasing reinforcement should increase satiation and reduce response rate. Decreasing reinforcement should reduce satiation and increase response rate. In contrast, if habituation occurs, then presenting a novel stimulus (e.g., a different reinforcer) should increase response rate to the original stimulus through dishabituation. ${ }^{3}$

Figure 1 presents the rate of responding (responses per minute) for the mean of all subjects during successive

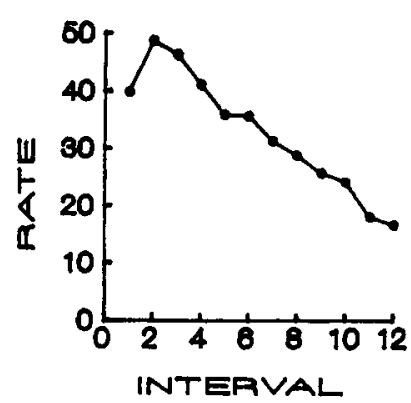

Figure 1. Rate of responding (responses per minute) for the mean of all subjects responding during successive 5-min intervals of first and last 30-session baseline sessions.

5-min intervals in the baseline sessions. The time of reinforcer delivery was excluded from all calculations of response rate. Results were averaged over the last five sessions for which each of the first and last 30-session baselines was conducted, and over both of those baselines. Results were averaged because a two-way (baseline $\times 5$ min interval) repeated measures analysis of variance (ANOVA) showed that the first and last baselines did not differ significantly from each other $(p<.05)$. The main effect of baseline was not significant $[F(1,3)=0.273]$, indicating that response rates averaged over the session did not differ. The interaction term was not significant $[F(11,33)=0.837]$, indicating that the within-session patterns of responding did not differ. The main effect of 5-min interval was significant, indicating that responding changed within the session $[F(11,33)=3.485]$. Figure 1 shows that response rate declined substantially late in the session; thus the experiment produced either habituation to or satiation for the reinforcer.

Figure 2 presents response rate (responses per minute) during successive 1-min intervals from Minutes 40-49 of the session. Each graph compares responding during one of the changed-reinforcement conditions (dashed line) with responding during the baselines (solid line). Again, results are those for the mean of all subjects. Results for the baselines were calculated as in Figure 1. Results for the changed reinforcement conditions were averaged over the first five sessions for which each change was presented.

Figure 2 shows that the patterns of responding differed during the baseline and the changed-reinforcement conditions. Responding was relatively flat over this time in the baseline. As Figure 1 shows, response rates averaged over the first and second of the 5-min intervals plotted in Figure 2 differed by only 1.6 responses per min. (Compare points 9 and 10 . Point 9 contains results for Minutes 40-44 because Minutes 0-4 are labeled "1" in Figure 1.) In contrast, responding changed substantially over this time in the changed-reinforcement conditions. The results of two-way (condition $\times 1$-min interval) ANOVAs confirmed that responding changed differently over time in the baseline and the changed-reinforcement conditions. The interaction terms were significant $(p<.05)$ when each changed-reinforcement condition was com- 


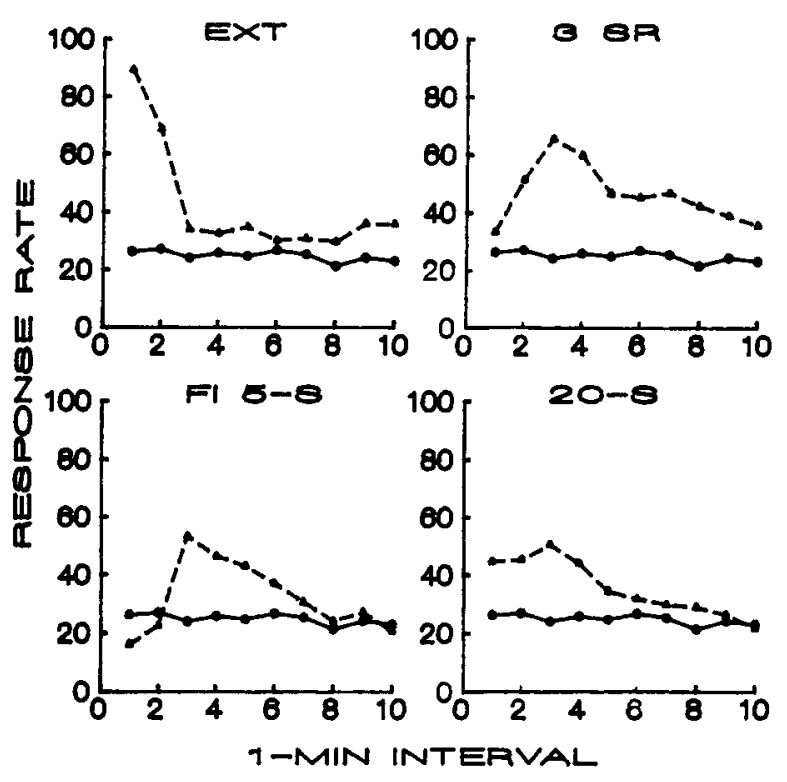

Figure 2. Response rate (responses per minute) for the mean of all subjects responding during successive 1-min intervals from Minutes $40-49$ of the session. Each graph compares responding when one of the changes in reinforcement was introduced (dashed line) to responding averaged over the first and last baselines (solid line).

pared with the averaged baseline [extinction, $F(9,27)=$ 12.899; FI 5-sec, $F(9,27)=8.231$; three reinforcers, $F(9,27)=4.537 ; 20$-sec reinforcers, $F(9,27)=2.791]$. The differences remained significant for three of the conditions when the baseline and changed-reinforcement conditions were compared only after the original reinforcers were restored [the last $8 \mathrm{~min}$ in Figure 2; interaction terms, FI 5 -sec, $F(7,21)=6.954$; three reinforcers, $F(7,21)=4.754 ; 20$-sec reinforcer, $F(7,21)=3.181]$. The patterns of responding did not differ significantly for the baseline and extinction conditions after the original reinforcers were restored $[F(7,21)=0.442]$.

The differences in response patterns between the baseline and the experimental conditions are consistent with habituation as an explanation for the late-session decreases in operant responding. After baseline reinforcers were restored (the last $8 \mathrm{~min}$ on each graph in Figure 2), response rates were faster during each of the changedreinforcement conditions than during baseline. In three of the four cases, the patterns of responding over time differed significantly between the baseline and the changed reinforcement conditions. The differences in responding between the baseline and the changed reinforcer condition cannot be attributed to persistence of the effect of the changed reinforcer itself. Some changes increased (e.g., 20 -sec reinforcer) and some decreased (e.g., FI $5-\mathrm{sec}$ ), responding relative to baseline while they were presented (first 2 min on each graph). Nevertheless, consistent with dishabituation, three of the four changes in the reinforcer increased response rates relative to baseline after they were removed. The failure to find a significant difference between extinction and the baseline condition is not entirely surprising. Producing dishabituation by omitting a stimulus, the "missing stimulus effect," has been difficult to demonstrate within the habituation literature (see, e.g., Groves \& Thompson, 1970).

The present results are not consistent with satiation. Three of the experimental manipulations delivered more reinforcers than baseline (FI 5-sec, three reinforcers, 20 -sec reinforcer). For example, subjects obtained an average of 20.5 reinforcers more per session during the FI 5 -sec condition than during baseline. The resulting increase in satiation should have reduced the following response rate. Instead, response rate increased substantially after all three manipulations. Also, contrary to satiation, extinction - the one operation that should have increased responding by decreasing satiation-produced the smallest, and nonsignificant, increase in response rate after the original reinforcers were restored.

To summarize, within-session changes in operant responding share 12 characteristics with habituated responding. Four of those characteristics were demonstrated after they were predicted by the habituation model for withinsession changes. To put the strength of finding 12 similar characteristics in perspective, the term habituation has been applied to phenomena that share as few as three of the characteristics of habituation (Eisenstein \& Peretz, 1973). Gill withdrawal in Aplysia, a generally accepted preparation for the study of habituation, shows six of Thompson and Spencer's (1966) original nine characteristics (Pinsker, Kupfermann, Castellucci, \& Kandel, 1970), although it might share more of a revised list. Finding so many empirical similarities suggests that habituation and within-session changes in operant responding share at least one common mechanism.

\section{Altering Several Satiety Factors Does not Alter the Within-Session Pattern of Responding}

As argued, understanding habituation leads to a detailed understanding of within-session changes in operant responding. In contrast, understanding satiation produces many incorrect predictions. To begin with, manipulation of several factors that control the consumption of food (satiety factors) produces no change in the within-session pattern of operant responding.

Before examining data that support this conclusion, we should address two frequently raised methodological issues. First, in all cases to be discussed, response rates averaged over the session changed appropriately with the experimental manipulation. Therefore, none of the following data can be dismissed by arguing that the experimental manipulation was too weak to alter satiation. Second, all of the following conclusions, like most of the conclusions we have reached in our laboratory, are based on reporting within-session changes in terms of both absolute (response rates) and normalized (i.e., proportions or percentages of total-session responses) measures. Therefore, none of the data can be dismissed by arguing that the presentation of proportions misrepresents the true nature of the within-session changes in responding. As discussed in the Appendix, absolute response rates and proportions 
may lead to different conclusions. However, that is never the case here.

Caloric density. Satiation (termination of consumption) may occur more quickly for higher than for lower calorie foods. Roll, McSweeney, Johnson, and Weatherly (1995, Experiment 1) examined within-session changes in responding when rats responded on multiple variable interval (VI) 60-sec VI 60-sec schedules. For one group of rats, reinforcers were $8 \%, 16 \%$, and $32 \%$ Polycose in different conditions. For the other group, reinforcers were $8 \%$ sucrose, $8 \%$ Polycose, or $0.15 \%$ saccharin. Sucrose and Polycose are high in calories. Saccharin provides no calories. The within-session patterns of operant responding did not change with the changes in caloric density for either group.

Prefeeding the subjects. Animals that are fed before the session should satiate more quickly than those that are not fed. In contrast, prefeeding should not change habituation if the food presented before the session differs sufficiently from the food presented during the session.

Roll et al. (1995, Experiment 2) examined responding by rats on a multiple VI 60 -sec VI 60 -sec schedule when no prefeedings were given. The amount of condensed milk reinforcer consumed up to the point in the session at which the peak response rate occurred was calculated for each rat to determine the amount of food required to initiate "satiation." Subjects were then divided into two groups that received either 1.0 or 2.0 times their predetermined amount of milk immediately before the session.

Food was infused directly into the stomach to precisely control consumption and to clearly separate the predictions of satiation and habituation. Subjects might habituate to the stimulus properties of food if it was presented orally during the prefeeding, but not if it was intubated. Finally, baseline was recovered. Prefeeding the subjects did not alter the within-session pattern of responding from its baseline form for either group.

Deprivation for the reinforcer. Altering the subject's deprivation for food should alter satiation. In contrast, changes in deprivation do not alter habituation to food for rats that are at least 18 days old (Swithers-Mulvey, Miller, \& Hall, 1991).

Roll et al. (1995, Experiment 2) placed rats on a multiple VI 60 -sec VI $60-\mathrm{sec}$ schedule while maintaining them at $75 \%, 85 \%$, or $95 \%$ of their free-feeding weights in different conditions. Consistent with habituation, the within-session patterns of responding did not differ for subjects maintained at different deprivations (see Figure Al in the Appendix).

It might be objected that rate of responding was relatively constant late in the session in this experiment. This might indicate that satiation did not occur, and, therefore, that the experiment did not test satiation as an explanation for the late-session decreases in responding. However, such an argument leaves us without an explanation for the differences in average response rates for subjects maintained at different weights. Response rates, averaged over the session, were $37.2,31.4$, and 21.0 responses per minute for the $75 \%, 85 \%$, and $95 \%$ subjects, respec- tively. Instead, the best description of all of the data is that responding may be relatively constant late in the experimental session even when differences in absolute response rates suggest that some groups were more satiated than others.

Reinforcer size. Animals should satiate more quickly when reinforcers are large than when they are small. Roll et al. (1995, Experiment 3) exposed rats to a multiple VI 60 -sec VI 60-sec schedule. Each reinforcer was $0.20 \mathrm{ml}$ of condensed milk plus $0,0.40$, or $0.80 \mathrm{ml}$ of condensed milk infused directly into the stomach in different conditions. The within-session pattern of responding did not change when the size of the reinforcer changed by a factor of 3, but the pattern did change when the reinforcer changed by a factor of 5 .

Roll et al. (1995) used an infusion procedure to control the exact size of the reinforcer, but their findings are not restricted to this procedure. Cannon and McSweeney (1995) placed pigeons on VI 30-sec and VI 60-sec schedules. The time of access to grain per reinforcer varied from 2 to $20 \mathrm{sec}$ in different conditions. The within-session patterns of responding did not differ for the 2-and 20-sec reinforcers when subjects responded on the VI 60-sec schedule, but they did differ when subjects responded on the VI 30-sec schedule. Therefore, within-session patterns of responding are relatively insensitive to the size of the reinforcer until reinforcers become quite large.

Caveat. These experiments show that several variables that are traditionally thought to alter satiation do not alter within-session changes in responding. The results do not establish that satiety variables, other than habituation, never influence within-session changes in responding. An effect of calories, postingestive consequences, and so on, that is independent of habituation to the sensory properties of food might be observed under conditions that are more extreme than those used in these experiments (e.g., higher rates of reinforcement, larger prefeedings).

The work of Roll et al. (1995, Experiment 3) might provide preliminary evidence that this is true. They found that responding decreased more strongly late in the session when each reinforcer was $0.2 \mathrm{ml}$ of milk taken by mouth plus $0.8 \mathrm{ml}$ of milk intubated into the stomach than when each reinforcer was $0.2 \mathrm{ml}$ of mouth milk alone. Habituation cannot account for this difference. Exposure to the sensory properties of food was identical in the two conditions ( $2 \mathrm{ml}$ of mouth milk). The steeper late-session decrease in responding for the intubation than for the mouth-only condition may indicate that postingestive satiety factors (e.g., stomach distension) sometimes contribute to within-session changes in responding. However, there are other potential explanations for this finding. For example, distension of the gut is aversive (e.g., Colburn, Coombs, Degnan, \& Rogers, 1989). Therefore, the punishers that accompanied the intubated reinforcers might have suppressed responding during the intubation, but not during the mouth-only condition. Future experiments should examine whether within-session changes in responding occur when all food reinforcers are delivered intragastrically. If they do, then a role for satiety 
factors, beyond habituation to the sensory properties of food, would be more conclusively established.

\section{Within-Session Response Patterns May Change When Satiety Should Not}

Altering several variables that should not alter satiety nevertheless changes the within-session patterns of operant responding. Weatherly et al. (1995, Experiment 1) showed that within-session patterns of responding sometimes changed even when total amount of food presented per session was constant. In their experiment, pigeons responded on five different multiple schedules that provided scheduled rates of reinforcement from 15 to 240 reinforcers per hour in different conditions. The size of the reinforcer (duration of access to food) changed with each change of schedule so that subjects obtained at most $300 \mathrm{sec}$ of reinforcement per session during all schedules. The timing of the reinforcer began when the pigeon's beak was inserted into the hopper to ensure that subjects did obtain reinforcers of different durations in the different conditions. The within-session pattern of responding changed with the change in schedule even though the total amount of reinforcement was constant.

These results are compatible with habituation. The amount of habituation should change when the rate of stimulus presentation changes (see, e.g., Thompson \& Spencer, 1966). They are less compatible with satiation. A relatively complicated model of satiation would be required to explain why the same $300 \mathrm{sec}$ of access to food produced different levels of satiation for different groups.

Within-session patterns of responding can differ for FI and VI, as well as for VI and multiple VI VI schedules that deliver the same rates of reinforcement (Figure 6 in McSweeney, Hinson, \& Cannon, 1996). Such results are consistent with habituation. Habituation may be faster and more pronounced when stimuli are delivered at fixed, rather than at variable, intervals of time (see, e.g., Broster \& Rankin, 1994; Davis, 1970; but see also Graham, 1973). The change in stimulus conditions from a VI to a multiple VI VI schedule might also alter habituation because habituation can occur to any stimulus, not just to reinforcers. In contrast, it is not clear how satiation can explain finding different within-session patterns of responding for schedules that provide similar amounts of food.

\section{Within-Session Changes in Responding Are Observed When No Ingestive Stimuli Are Delivered}

Habituation can occur to noningestive (e.g., lights, tones), as well as to ingestive (e.g., food, water), stimuli. Satiation is often restricted to ingestive stimuli. Consistent with habituation, punishers (see, e.g,. Azrin, 1960) and negative reinforcers (see, e.g., Jerome et al., 1958) of weak or intermediate intensity lose their effectiveness late in the session. Systematic within-session changes in responding, similar to those observed with food, are also observed when stimuli with no ingestive consequences (see, e.g., lights) serve as reinforcers (e.g., Kish, 1966). Although some authors speak of "stimulus satiation" when referring to changes in the effectiveness of "neutral" stimuli (see, e.g., Glanzer, 1953), this is a metaphorical use. It should be avoided unless one is also willing to argue that subjects satiate to the termination of loud noises or electric shocks.

Within-session changes are also observed when no external reinforcers are presented. For example, within-session changes in leverpressing have been observed before conditioning begins (e.g., Schoenfeld, Antonitis, \& Bersh, 1950) and during extinction (spontaneous recovery). Habituation, but not satiation, can explain these changes if it is assumed that subjects habituate to the stimulus properties of their own responding (responding before conditioning) or to the experimental context that was established as a discriminative stimulus during conditioning (extinction).

It might be objected that there is no reason to assume that the decreasing pattern of responding during sessions of extinction (spontaneous recovery) is produced by the same variables that produce within-session changes in responding during conditioning. However, again, empirical similarities between extinction and habituation suggest they share at least one common explanation. Both habituated and extinguished responding may be restored by the presentation of a novel stimulus (dishabituation or disinhibition; see, e.g., Thompson \& Spencer, 1966). Both habituated and extinguished responding recover over time (spontaneous recovery; see, e.g., Thompson \& Spencer, 1966). Spontaneous recovery may be smaller when stimulus repetition continues after responding ceases (habituation or extinction below zero; see, e.g., Thompson \& Spencer, 1966). Finally, both decreases in responding are well described by a negative exponential function (see, e.g., Thompson \& Spencer, 1966). Again, finding similar empirical properties suggests at least one common mechanism (see, e.g., Humphrey, 1930; Thompson \& Spencer, 1966; Windsor, 1930; but see also Kling \& Stevenson, 1970; Razran, 1956).

\section{FORMAL ARGUMENTS THAT FAVOR HABITUATION}

\section{Specificity}

Several formal arguments also favor habituation over satiation. Habituation to the sensory properties of the ingestive stimulus (see, e.g., the taste) is one of several factors that may contribute to satiation for that stimulus (e.g., Swithers \& Hall, 1994). Therefore, attributing withinsession changes to habituation is more specific than attributing them to satiation. Attributing within-session changes to satiation does not specify which of many factors produces the within-session changes (e.g., the nutritional state of the animal, circulating levels of glucose, stomach loading). Attributing within-session changes to habituation specifies that exposure to the sensory aspects of the reinforcer is the critical variable. 


\section{Early-Session Increases in Responding Are Expected if Habituation Produces the Late-Session Decreases}

Neither satiation nor habituation explains the earlysession increases in responding. Both must be supplemented by an additional factor. However, sensitization, an increase in responsiveness to a stimulus, is often found during the first presentations of a stimulus, before habituation becomes apparent (see, e.g., Groves \& Thompson, 1970). Therefore, the literature on habituation predicts that early-session increases in responding should occur. The literature provides a label for those increases-"sensitization"- and a characterization of the processes underlying the increases (see, e.g., Groves \& Thompson, 1970). In contrast, satiation provides no reason to expect, and no characterization of, the early-session increases in responding.

\section{Preservation of Common Explanations in Operant and Classical Conditioning}

Operant researchers strongly prefer satiation to habituation as an explanation for why reinforcers lose their effectiveness with presentation. In contrast, researchers in classical conditioning often use the term habituation to describe the loss of effectiveness of a US with its repeated presentation. For example, the size of the UR may decrease during conditioning (conditioned diminution of the UR; see, e.g., Kimmel, 1966). Classical conditioning is usually weaker when several USs are presented before conditioning begins than when they are not (the US preexposure effect; see, e.g., Mis \& Moore, 1973). Conditioning is usually weaker when a US is presented immediately before a conditioned stimulus (CS)-US pairing than when it is not (priming by the US; see, e.g., Terry, 1976). Conditioning is usually also weaker when a CS is paired with a weak US before it is paired with a strong US than when it is not (the Hall-Pearce Effect; Hall \& Pearce, 1979). These effects are often at least partially attributed to habituation (see, e.g., Randich \& LoLordo, 1979; Wagner, 1976), but, to the best of our knowledge, not to satiation.

We believe that a single explanation should be offered for the effects of presenting USs and reinforcers. Providing a single explanation is more parsimonious. It is also in accord with current usage: The term reinforcer is often used to refer to the US in Pavlovian procedures (see, e.g., Davidson \& Rescorla, 1986). Finally, some evidence suggests that the effects of presenting reinforcers and USs are similar. McSweeney, Swindell, and Weatherly (1996b) studied responding on two procedures that are often considered to be classical conditioning: autoshaping and negative automaintenance. Rate of responding changed systematically within sessions in a manner similar to the within-session changes observed in the operant literature. In particular, the within-session changes were larger, peaked earlier, and were less symmetrical around the middle of the session, when the time between successive USs (reinforcers) was shorter than when it was longer. Finding common functional changes in the within-session patterns during both types of conditioning suggests that within-session changes in responding are produced by similar, not different, factors in the two cases.

Habituation provides a better candidate for a common explanation than satiation. To begin with, the US in classical conditioning is often a noningestive stimulus, such as a shock, to which the term satiation is not usually applied. But also, the effects of exposure to the US in classical conditioning are strikingly similar to the effects of exposure to the CS. The salience of the CS may change during conditioning (see, e.g., Pearce \& Hall, 1980). Classical conditioning is usually weaker when several CSs are presented before conditioning begins than when they are not (latent inhibition; see, e.g., Lubow, 1989). Conditioning is usually weaker when a CS is presented immediately before a CS-US pairing than when it is not (priming by the CS; see, e.g., Pfautz \& Wagner, 1976). In addition, habituation to both the CS and the US may contribute to learned irrelevance (see, e.g., Mackintosh, 1973), the finding that conditioning is retarded following uncorrelated presentations of the CS and US (see, e.g., Bonardi \& Hall, 1996).

This argument should not be misinterpreted. We are not arguing that habituation can provide a complete explanation for all of these phenomena. Assessment of the role of habituation in each phenomenon is far beyond the scope of this paper, although many classical conditioning experiments lack adequate procedures to control for habituation and its associated phenomena (dishabituation, spontaneous recovery, etc.). Our point is only that the effects of presenting a CS and a US in classical conditioning are similar, suggesting that they share at least one common mechanism. Habituation provides one of many candidates for this mechanism. Satiation does not. Satiation could account for the effects of presenting some ingestive USs but a second variable would have to account for the highly similar effects of presenting CSs and noningestive USs.

\section{Preservation of Common Descriptions for Appetitive and Aversive Stimuli}

Parallel to the results for positive reinforcers, an earlysession increase in response rate (warmup) is often observed when aversive stimuli are delivered in escape (see, e.g., Dinsmoor, 1962), avoidance (see, e.g., Hoffman, Fleshler, \& Chorny, 1961), and punishment procedures (see, e.g., Azrin, 1956). Sensitization, habituation's companion process, provides a potential explanation for warmup.

Punishers (see, e.g., Azrin, 1960) and negative reinforcers (see, e.g., Jerome et al., 1958) of weak or intermediate intensity may lose their effectiveness late in the session. Habituation may describe this loss of effectiveness. Habituation is also compatible with the finding that warmup for avoidance is often observed without a late- 
session decrease in responding. Habituation does not always occur when very strong stimuli (e.g., intense shocks) are delivered (see, e.g., Groves \& Thompson, 1970).

In contrast, satiation provides no explanation for changes in the effectiveness of aversive stimuli. Therefore, attributing within-session changes in responding for positive reinforcers to satiation would introduce an undesirable asymmetry in the explanations of the effects of appetitive and aversive stimuli.

\section{IMPLICATIONS}

The distinction between attributing late-session decreases in operant responding to satiation and attributing them to habituation may seem trivial, but it actually has many implications. We have already discussed how the idea that subjects habituate to reinforcers challenges traditional assumptions that habituation alters only reflexive behavior and that it occurs only to biologically irrelevant stimuli. Other implications will be discussed here (see also McSweeney, Hinson, \& Cannon, 1996.)

\section{The Integration of Motivational Variables Into Associative Learning}

Many theories describe the conditions under which animals form associations between stimuli or between responses and stimuli (e.g., Rescorla \& Wagner, 1972). Such theories of "learning" often ignore questions about when animals will display those associations. Recently, theorists have attempted to integrate motivational or performance variables into learning theories (e.g., Balleine, Garner, Gonzalez, \& Dickinson, 1995; Matzel, Shuster, \& Miller, 1987). The present argument may contribute to this effort. If sensitization-habituation occurs when reinforcers, CSs, or USs are repeatedly presented, then response rates may change during conditioning sessions even when associative factors are constant. Therefore, understanding sensitization and habituation to reinforcers may help to explain motivational changes.

\section{A Relatively General Description of the Temporal Patterning of Behavior}

As argued earlier, habituation may contribute to satiation itself (see, e.g., Swithers-Mulvey \& Hall, 1992), to the temporal patterning of responding during extinction (see, e.g., Thompson \& Spencer, 1966), to changes in the effectiveness of aversive stimuli, and to several characteristics of classically conditioned responding. We will briefly discuss several additional phenomena to which habituation might contribute.

Habituation, but not satiation, might contribute to the frustration effect reported by Amsel (e.g., 1958, 1962). The frustration effect is an increase in the speed of running in an alley after the omission of an "expected" reinforcer. If habituation builds up with the presentation of reinforcers, then the omission of an expected reinforcer might increase response rate by producing dishabituation.
Much evidence would be required to confirm this explanation for the frustration effect, but Figure 2 provides some initial support. The upper left graph shows a frustration effect for keypecking. That is, the rate of keypecking increased immediately after reinforcer omission, just as speed of alley running increases. Future experiments should test additional implications of this view. For example, if the present explanation is correct, then running should be faster after any large change in the reinforcer, not just after its omission.

Habituation, but not satiation, might contribute to changes in responding with the repeated delivery of drugs. For exarnple, when rats self-administer cocaine, responding is often fast early in the session and slower later (see, e.g., Weiss et al., 1992). These changes are usually attributed to pharmacological effects of the drug. That is, changes in responding are often attributed to rats regulating their levels of dopamine (e.g., Petit \& Justice, 1989; Weiss et al., 1992) or to cocaine producing stereotyped responding that interferes with operant responding (see, e.g,. Woods, Winger, \& France, 1987). However, some of these changes may be produced by habituation to drug stimuli rather than by other pharmacological effects.

In support of this idea, Roll, McSweeney, Meil, Hinson, and See (1996) found that the time at which responding for cocaine reinforcers slowed was independent of the dosage of cocaine that the rats received. They also showed that the late-session decreases in responding (the slowing of responding) occurred similarly when subjects responded to produce food and when they responded to produce food plus cocaine. Both of these results suggest that the slowing of responding for cocaine is not solely attributable to the pharmacological effect of the drug. Pharmacological effects should be correlated with the dosage of the drug, but the slowing of responding may not be.

Finally, habituation, but not satiation, might also contribute to temporal changes in human vigilance (see, e.g., Mackworth, 1968) and in spontaneously occurring behaviors (e.g., activity, exploration, and locomotion; e.g., Montgomery, 1953a, 1953b). It might be objected that habituation has already been examined as an explanation for these phenomena and has met with mixed success (e.g., exploration; Poucet, Durup, \& Thinus-Blanc, 1988; Thompson \& Spencer, 1966; but see also Williams, Hamilton, \& Carlton, 1974, 1975). In our opinion, however, the contribution of habituation has not been adequately tested. To give only one example, Davies and Parasuraman (1982) argued that habituation occurs too quickly to account for decreases in human vigilance over $30 \mathrm{~min}$ to $4 \mathrm{~h}$. Their conclusion ignores the fact that habituation occurs at different rates for different preparations (see, e.g., Hinde, 1970).

If further research confirmed that similar processes govern responding in all of these situations, then habituation might provide a relatively simple and truly general description of the temporal patterning of responding in many situations. In contrast, satiation would link the operant literature to fewer behavioral phenomena. 


\section{Directions for Future Research}

Attributing the late-session decreases in responding to habituation points to different directions for future research than does attributing them to satiation. To begin with, it allows use of the extensive literature on habituation to make additional predictions about the characteristics of within-session changes in responding. For example, habituation below zero (Thompson \& Spencer, 1966) might be observed. It also raises a number of questions that remain to be answered. A few will be mentioned here.

How does habituation reduce reinforcer value? The manner in which habituation to a reinforcer reduces the effectiveness of that reinforcer is not known. The perceived intensity of the reinforcer might decrease with its repeated presentation. Alternatively, the reinforcer might lose its "hedonic value" while remaining relatively constant in intensity. Hedonic value may be measured by subjective ratings of pleasantness (see, e.g., B. J. Rolls \& E. T. Rolls, 1982) or by behaviors associated with pleasure or distaste (see, e.g., Berridge, 1991).

A few data favor loss of hedonic value over loss of intensity. Many studies show that the hedonic value of food or water decreases with the time spent eating or drinking and recovers in the absence of these activities (e.g., Berridge, 1991; Logue, 1991, p. 93; B. J. Rolls \& E. T. Rolls, 1982, p. 82). In contrast, few data show that the stimulus intensity of food or water changes with consumption. For example, E. T. Rolls, B. J. Rolls, and Rowe (1983) reported that changes in the hedonic value of food with consumption were accompanied by only minor and uncorrelated changes in the intensity of its taste.

To what aspects of the reinforcer do subjects habituate? Reinforcers have a number of stimulus characteristics (e.g., size, texture, color, taste, temperature, brightness, timing, etc.) The exact characteristics to which subjects habituate are not known. Figure 2 may help to clarify this issue. Although other arguments could be made (see, e.g., Groves \& Thompson, 1970), some theorists argue that changing a characteristic of a stimulus disrupts habituation only if subjects habituated to that characteristic. For example, Sokolov (1963) argued that subjects create a model of the stimulus. Habituation occurs when an incoming stimulus matches the subject's model. Therefore, if a change in the stimulus disrupts habituation, the changed characteristic was present in the subject's model. By that reasoning, Figure 2 shows that subjects habituated to the presence (extinction), timing (FI 5 -sec), duration (20-sec reinforcer), and number (three reinforcers) of the reinforcer.

The results of other studies are also consistent with the conclusion that subjects habituate to several characteristics of the reinforcer. Changing the timing (see, e.g., McSweeney, Hinson, \& Cannon, 1996, Figure 6), duration (see, e.g., Cannon \& McSweeney, 1995), and number (i.e., rate; see, e.g., McSweeney, 1992) of reinforcers across conditions may alter the within-session pattern of responding. Therefore, on the assumption that habituation produces within-session changes in responding, subjects probably habituated to at least those aspects of the reinforcers.

Do subjects habituate to other aspects of the experimental situation? We have focused on habituation to the reinforcer as an explanation for the late-session decreases in operant responding because changes in reinforcer effectiveness clearly do contribute to the within-session patterns of responding (see, e.g., McSweeney, Weatherly, \& Swindell, 1996a). However, McSweeney, Hinson, and Cannon (1996) argued that habituation to other aspects of the experimental situation might also occur if those aspects were presented repeatedly or for a prolonged time. Under some circumstances, habituation to these other aspects could alter the rate of operant responding.

A few data support this idea. McSweeney, Swindell, and Weatherly (1997) began the experimental session 0 , $5,10,15$, or $30 \mathrm{~min}$ after the subject had been placed in the experimental enclosure, determined randomly. During the delay to the beginning of the session, the houselight was not illuminated, no reinforcers were available, and subjects responded little or not at all. Nevertheless, the early-session increase in responding was smaller when the session was delayed than when it was not. Although there are alternative explanations for this finding, such results would be observed if the experimental context acted as a discriminative stimulus for operant responding and subjects began to sensitize and habituate to that stimulus as soon as they were placed in the enclosure. Whether habituation to other stimuli (e.g., discriminative stimuli) also contribute to within-session changes remains to be established.

\section{SUMMARY}

Contrary to intuition, strong empirical and formal arguments favor habituation over satiation as an explanation for late-session decreases in operant responding, at least under the moderate conditions of reinforcement that are used in most experiments. To begin with, the characteristics of habituation and of within-session changes in operant responding are strikingly similar, suggesting that they share at least one common mechanism. Several manipulations that are known to alter satiety do not change within-session patterns of responding, and withinsession patterns may change under conditions that should not alter satiety. Habituation, but not satiation, can explain within-session changes in responding when "neutral" (e.g.. lights) and aversive (e.g., shocks) stimuli are presented. Habituation is a more specific explanation than satiation and it suggests an empirically based explanation for the early-session increases in responding. Habituation also offers a common explanation for the effects of presenting appetitive and aversive stimuli and for the effects 
of presenting operant reinforcers and Pavlovian USs. Finally, habituation has greater potential as a unifying theoretical construct.

Arguing that habituation to the reinforcer contributes to within-session changes in operant responding has a number of implications. It requires abandoning the traditional assumption that habituation occurs only for reflexive behaviors and for biologically irrelevant stimuli. It may help to integrate motivational variables into theories of conditioning and may provide a relatively general description of the temporal changes in responding in a wide variety of situations. Finally, it provides novel directions for future research. In particular, experiments should clarify exactly how habituation alters the effectiveness of a reinforcer.

\section{REFERENCES}

AMSEL, A. (1958). The role of frustrative nonreward in noncontinuous reward situations. Psychological Bulletin, 55, 102-119.

AMSEL, A. (1962). Frustrative nonreward in partial reinforcement and discrimination learning: Some recent history and a theoretical extension. Psychological Review, 69, 306-328.

AzRIN, N. H. (1956). Some effects of two intermittent schedules of immediate and non-immediate punishment. Journal of Psychology, 42, 3-21.

Azrin, N. H. (1960). Sequential effects of punishment. Science, 131, 605-606.

Balleine, B. W., Garner, C., Gonzalez, F., \& Dickinson, A. (1995). Motivational control of heterogeneous instrumental chains. Journal of Experimental Psychology: Animal Behavior Processes, 21, 203-217.

BAUM, W. M. (1974). On two types of deviation from the matching law: Bias and undermatching. Journal of the Experimental Analysis of Behavior, 22, 231-242.

BERRIDGE, K. C. (1991). Modulation of taste affect by hunger, caloric satiety, and sensory-specific satiety in the rat. Appetite, 16, 103-120.

BonARDI, C. \& HALL, G. (1996). Learned irrelevance: No more than the sum of CS and US preexposure effects? Journal of Experimental Psychology: Animal Behavior Processes, 22, 183-191.

Broster, B. S., \& RANKIN, C. H. (1994). Effects of changing interstimulus interval during habituation in Caenorhabditis elegans. Behavioral Neuroscience, 108, 1019-1029.

CANNON, C. B., \& MCSWEENEY, F. K. (1995). Within-session changes in responding when rate and duration of reinforcement vary. Behavioural Processes, 34, 285-292.

Catania, A. C. (1979), Learning. Englewood Cliffs, NJ: Prentice-Hall.

Colburn, R. W., Coombs, D. W., Degnan, C. C., \& Rogers, L. L. (1989). Mechanical visceral pain model: Chronic intermittent intestinal distension in the rat. Physiology \& Behavior, 45, 191-197.

Davidson, T. L., \& Rescorla, R. A. (1986). Transfer of facilitation in the rat. Animal Learning \& Behavior, 14, 380-386.

Davies, D. R., \& Parasuraman, R. (1982). The psychology of vigilance. New York: Academic Press.

Davis, M. (1970). Effects of interstimulus interval length and variability on startle-response habituation in the rat. Journal of Comparative \& Physiological Psychology, 72, 177-192.

Dinsmoor, J. A. (1962). Variable-interval escape from stimuli accompanied by shock. Journal of the Experimental Analysis of Behavior, $5,41-47$.

Eisenstein, E. M., \& Peretz, B. (1973). Comparative aspects of habituation in invertebrates. In H. V. S. Peeke \& M. J. Herz (Eds.), Habituation: Vol. 2. Physiological substrates (pp. 1-31). New York: Academic Press.

GlanZer, M. (1953). Stimulus satiation: An explanation of spontaneous alternation and related phenomena. Psychological Review, 60, 257-268.
GraHam, F. K. (1973). Habituation and dishabituation of responses innervated by the autonomic nervous system. In H. V. S. Peeke \& M. J. Herz (Eds.), Habituation: Vol. 1. Behavioral Studies (pp. 163-218). New York: Academic Press.

Groves, P. M., \& Thompson, R. F. (1970). Habituation: A dual-process theory. Psychological Review, 77, 419-450.

Hall, G., \& Pearce, J. M. (1979). Latent inhibition of a CS during CS-US pairings. Journal of Experimental Psychology: Animal Behavior Processes, 5, 31-42.

HINDE, R. A. (1970). Behavioral habituation. In G. Horn \& R. A. Hinde (Eds.), Short-term changes in neural activity and behavior (pp. 3-40). Cambridge: Cambridge University Press.

Hoffman, H. S., Fleshler, M., \& Chorny, H. (1961). Discriminated bar-press avoidance. Journal of the Experimental Analysis of Behavior, 4, 309-316.

Humphrey, G. (1930). Extinction and negative adaptation. Psychological Review, 37, 361-363.

Jerome, E. A., Moody, J. A., Connor, T. J., \& Ryan, J. (1958). Intensity of illumination and the rate of responding in a multiple-door situation. Journal of Comparative \& Physiological Psychology, 51, 47-49.

KilleEN, P. R. (1995). Economics, ecologics, and mechanics: The dynamics of responding under conditions of varying motivation. Journal of the Experimental Analysis of Behavior, 64, 405-431.

KIMMEL, H. D. (1966). Inhibition of the unconditioned response in classical conditioning. Psychological Review, 73, 232-240.

KIMmeL, H. D. (1973). Habituation, habituability and conditioning. In H. V. S. Peeke \& M. J. Herz (Eds.), Habituation: Vol. l. Behavioral Studies (pp. 219-238). New York: Academic Press.

Kish, G. B. (1966). Studies of sensory reinforcement. In W. K. Honig (Ed.), Operant behavior: Areas of research and application (pp. 109159). New York: Appleton-Century-Crofts.

KLing, J. W., \& Stevenson, J. G. (1970). Habituation and extinction. In G. Horn \& R. A. Hinde (Eds.), Short-term changes in neural activity and behavior (pp. 41-61). Cambridge: Cambridge University Press.

LEATON, R. N., \& TIGHE, T. J. (1976). Comparisons between habituation research at the developmental and animal-neurophysiological levels. In T. J. Tighe \& R. N. Leaton (Eds.), Habituation: Perspectives from child development, animal behavior and neurophysiology (pp. 321-340). New York: Wiley.

LoGUE, A. W. (1991). The psychology of eating and drinking: An introduction (2nd ed.). New York: W. H. Freeman.

LuBOw, R. E. (1989). Latent inhibition and conditioned attention theory. Cambridge: Cambridge University Press.

MACKINTOSH, N. J. (1973). Stimulus selection: Learning to ignore stimuli that predict no change in reinforcement. In R. A. Hinde \& J. S. Hinde (Eds.), Constraints on learning (pp. 75-96). London: Academic Press.

MACKWORTH, J. F. (1968). Vigilance, arousal and habituation. Psychological Review, 75, 308-322.

Matzel, L. D., Shuster, K., \& Miller, R. R. (1987). Covariation in conditioned response strength between stimuli trained in compound. Animal Learning \& Behavior, 15, 439-447.

MCSWEENEY, F. K. (1992). Rate of reinforcement and session duration as determinants of within-session patterns of responding. Animal Learning \& Behavior, 20, 160-169.

McSweeney, F. K., Hatfield, J., \& Allen, T. M. (1990). Withinsession responding as a function of post-session feedings. Behavioural Processes, 22, 177-186.

McSweeney, F. K., Hinson, J. M., \& Cannon, C. B. (1996). Sensitization-habituation may occur during operant conditioning. Psychological Bulletin, 120, 256-271.

MCSWEENEY, F. K., \& JoHNSON, K. S. (1994). The effect of time between sessions on within-session patterns of responding. Behavioural Processes, 31, 207-218.

MCSweEney, F. K., \& Roll, J. M. (1993). Responding changes systematically within sessions during conditioning procedures. Journal of the Experimental Analysis of Behavior, 60, 621-640.

McSweeney, F. K., Roll, J. M., \& CanNon, C. B. (1994). The generality of within-session patterns of responding: Rate of reinforcement and session length. Animal Learning \& Behavior, 22, 252-266. 
MCSWeEney, F. K., Roll, J. M., \& Weatherly, J. N. (1994). Withinsession changes in responding during several simple schedules. Journal of the Experimental Analysis of Behavior, 62, 109-132.

McSWeEney, F. K., Swindell, S., \& Weatherly, J. N. (1996a). Within-session changes in adjunctive and instrumental responding. Learning \& Motivation, 27, 408-427.

McSweeney, F. K., SWindell, S., \& Weatherly, J. N. (1996b) Within-session changes in responding during autoshaping and automaintenance procedures. Journal of the Experimental Analysis of Behavior, 66, 51-61.

MCSWEENEY, F. K., Swindell, S., \& Weatherly, J. N. (1996c). Withinsession changes in responding during concurrent schedules with different reinforcers in the components. Journal of the Experimental Analysis of Behavior, 66, 369-390.

McSweeney, F. K., SWindell, S., \& Weatherly, J. N. (1997, November). Exposure to context alters within-session changes in responding. Paper presented at the annual meeting of the Psychonomic Society, Philadelphia.

MCSweeney, F. K., Weatherly, J. N., \& Roll, J. M. (1995). Withinsession changes in responding during concurrent schedules that employ two different operanda. Animal Learning \& Behavior, 23, 237-244.

McSweeney, F. K., Weatherly, J. N., Roll, J. M., \& Swindell, S. (1995). Within-session patterns of responding when the operandum changes during the session. Learning \& Motivation, 26, 403-420.

McSweeney, F. K., Weatherly, J. N., \& SWindell, S. (1995). Prospective factors contribute little to within-session changes in responding. Psychonomic Bulletin \& Review, 2, 234-238.

McSweeney, F. K., Weatherly, J. N., \& Swindell, S. (1996a). Reinforcer value may change within experimental sessions. Psychonomic Bulletin \& Review, 3, 372-375.

McSweeney, F. K., Weatherly, J. N., \& Swindell, S. (1996b). Within-session changes in responding during delayed matching-tosample and discrimination procedures. Animal Learning \& Behavior, 24, 290-299.

Melville, C. L., Rue, H. C., Rybiski, L. R., \& Weatherly, J. N. (1997). Altering reinforcer variety or intensity changes the withinsession decrease in responding. Learning \& Motivation, 28, 609-621

Melville, C. L., Rybiski, L. R., \& KamRani, B. (1996). Within-session responding as a function of force required for lever press. Behavioural Processes, 37, 217-224.

Millenson, J. R. (1967). Principles of behavioral analysis. New York: Macmillan.

Mis, F. W., \& MoORE, J. W. (1973). Effect of preacquisition UCS exposure on classical conditioning of the rabbit's nictitating membrane response. Learning \& Motivation, 4, 108-114.

Montgomery, K. C. (1953a). The effect of activity deprivation upon exploratory behavior. Journal of Comparative \& Physiological Psychology, 46, 438-441.

Montgomery, K. C. (1953b). The effect of hunger and thirst drives upon exploratory behavior. Journal of Comparative \& Physiological Psychology, 46, 315-319.

PALYA, W. L., \& WALTER, D. E. (1997). Rate of a maintained operant as a function of temporal position within a session. Animal Learning \& Behavior, 25, 291-300.

Pearce, J. M., \& Hall, G. (1980). A model of Pavlovian learning: Variations in the effectiveness of conditioned but not unconditioned stimuli. Psychological Review, 87, 532-552

Petit, H. O., \& Justice, J. B., JR. (1989). Dopamine in the nucleus accumbens during cocaine self-administration as studied by in vivo microdialysis. Pharmacology, Biochemistry \& Behavior, 34, 899-904.

Pfautz, P. L., \& Wagner, A. R. (1976). Transient variations in responding to Pavlovian conditioned stimuli have implications for the mechanisms of "priming." Animal Learning \& Behavior, 4, 107-112.

Pinsker, H., Kupfermann, I., Castellucci, V., \& Kandel, E. (1970). Habituation and dishabituation of the gill-withdrawal reflex in Aplysia. Science, 167, 1740-1742.

Poucet, B., Durup, M., \& Thinus-Blanc, C. (1988). Short-term and long-term habituation of exploration in rats, hamsters and gerbils. Behavioural Processes, 16, 203-211.
Randich, A., \& LoLordo, V. M. (1979). Associative and nonassociative theories of the UCS preexposure phenomenon: Implications for Pavlovian conditioning. Psychological Bulletin, 86, 523-548.

Razran, G. (1956). Extinction re-examined and re-analyzed: A new theory. Psychological Review, 63, 39-52.

RESCORLA, R. A., \& WAGNER, A. R. (1972). A theory of Pavlovian conditioning: Variations in the effectiveness of reinforcement and nonreinforcement. In A. H. Black \& W. F. Prokasy (Eds.), Classical conditioning $I I$ (pp. 64-99). New York: Appleton-Century-Crofts.

RoLL, J. M., \& MCSWEENEY, F. K. (1997). Within-session changes in operant responding when gerbils (Meriones ungiculatus) serve as subjects. Current Psychology, 15, 340-345.

Roll, J. M., MCSWEeney, F. K., JohnSon, K. S., \& WeatherLy, J. N. (1995). Satiety contributes little to within-session decreases in responding. Learning \& Motivation, 26, 323-341.

Roll, J. M., McSweeney, F. K., Meil, W. M., Hinson, J. M., \& See, R. E. (1996). A preliminary examination of some effects of cocaine on within-session patterns of responding. Behavioural Processes, 37, 9-20.

Rolls, B. J., \& Rolls, E. T. (1982). Thirst. Cambridge: Cambridge University Press.

Rolls, E. T., Rolls, B. J., \& Rowe, E. A. (1983). Sensory-specific and motivation-specific satiety for the sight and taste of food and water in man. Physiology \& Behavior, 30, 185-192.

RYBISKI, L. R. (1996). A test for stimulus-specificity in the within-session pattern of responding. Unpublished master's thesis, McNeese State University, Lake Charles, LA.

SAVORY, C. J. (1988). Rates of eating in domestic fowls in relation to changing food deficits. Appetite, 10, 57-65.

Schoenfeld, W. N., ANTONITIS, J. J., \& Bersh, P. J. (1950). Unconditioned response rate of the white rat in a barpressing apparatus. Journal of Comparative \& Physiological Psychology, 43, 41-48.

SokoLov, E. N. (1963). Perception and the conditioned reflex. New York: MacMillan.

Solomon, R. L., \& CORBIT, J. D. (1974). An opponent-process theory of motivation: I. Temporal dynamics of affect. Psychological Review, 81, 119-145.

SPEAR, N. E. (1973). Retrieval of memory in animals. Psychological Review, 80, 163-194.

Swithers, S. E., \& HalL, W. G. (1994). Does oral experience terminate ingestion? Appetite, 23, 113-138.

Swithers-MulveY, S. E., \& Hall, W. G. (1992). Control of ingestion by oral habituation in rat pups. Behavioral Neuroscience, 106, 710-717.

Swithers-Mulvey, S. E., \& HALL, W. G. (1993). Integration of oral habituation and gastric signals in decerebrate rat pups. American Journal of Physiology, 265, R216-R219.

Swithers-Mulvey, S. E., Miller, G. L., \& Hall, W. G. (1991). Habituation of oromotor responding to oral infusions in rat pups. $A p$ petite, 17, 55-67.

TERRY, W. S. (1976). Effects of priming unconditioned stimulus representation in short-term memory on Pavlovian conditioning. Journal of Experimental Psychology: Animal Behavior Processes, 2, 354-369.

Teyler, T. J., Chiana, N., DiScenna, P., \& Roemer, R. A. (1984). Habituation of central nervous system evoked potentials: Intrinsic habituation examined in neocortex, allocortex and mesencephalon. In H. V. S. Peeke \& L. Petrinovich (Eds.), Habituation, sensitization and behavior (pp. 251-285). New York: Academic Press.

THOMPSON, R. F., \& SPENCER, W. A. (1966). Habituation: A model phenomenon for the study of neuronal substrates of behavior. Psychological Review, 73, 16-43.

THORPE, W. H. (1966). Learning and instinct in animals (pp. 55-75) Cambridge, MA: Harvard University Press.

Venator, E. R., Boothe, M., \& Hallford, W. (1997, May). Effects of within-session changes in reinforcer duration on within-session changes in the rate of an operant. Poster presented at the meeting of the Association for Behavior Analysis, Chicago.

VINOGRADOVA, O. S. (1970). Registration of information and the limbic system. In G. Horn \& R. A. Hinde (Eds.), Short-term changes in neural activity and hehavior (pp. 95-140). Cambridge: Cambridge University Press 
WAGNER, A. R. (1976). Priming in STM: An information-processing mechanism for self-generated or retrieval-generated depression in performance. In T. J. Tighe \& R. N. Leaton (Eds.), Habituation: Perspectives from child development, animal behavior and neurophysiology (pp. 95-128). New York: Wiley.

Weatherly, J. N., MCSweeney, F. K., \& Swindell, S. (1995). On the contributions of responding and reinforcement to within-session patterns of responding. Learning \& Motivation, 26, 421-432.

Weiss, F., Hurd, Y. L., Ungerstedt, U., Markou, A., Plotsky, P. M., \& Коов, G. F. (1992). Neurochemical correlates of cocaine and ethanol self-administration. In P. W. Kalivas \& H. H. Samson (Eds.) The neurobiology of drug and alcohol addiction (Annals of the New York Academy of Sciences, Vol. 654, pp. 220-241). New York: New York Academy of Sciences.

Williams, J. M., Hamilton, L. W., \& Carlton, P. L. (1974). Pharmacological and anatomical dissociation of two types of habituation. Journal of Comparative \& Physiological Psychology, 87, 724-732.

Williams, J. M., Hamilton, L. W., \& Carlton, P. L. (1975). Ontogenetic dissociation of two classes of habituation. Journal of Comparative \& Physiological Psychology, 89, 733-737.

WINDSOR, A. L. (1930). Experimental extinction and negative adaptation. Psychological Review, 37, 174-178.

Woods, J. H., Winger, G. D., \& FrancE, C. P. (1987). Reinforcing and discriminative stimulus effects of cocaine: Analysis of pharmacological mechanisms. In S. Fisher, A. Raskin, \& E. H. Uhlenhuth (Eds.), Cocaine: Clinical and biobehavioral aspects (pp. 21-65). New York: Oxford University Press.

Wyers, E. J., Peeke, H. V. S., \& Herz, M. J. (1973). Behavioral habituation in invertebrates. In H. V. S. Peeke \& M. J. Herz (Eds.), Habituation: Vol. 1. Behavioral studies (pp. 1-57). New York: Academic Press.

\section{NOTES}

1. Throughout this paper, we argue that habituation occurs to reinforcers. The use of the term reinforcer in this context is technically incorrect. We actually argue that habituation occurs to stimuli, such as food and water, that are used as reinforcers. These stimuli need not act as reinforcers for habituation to occur. For example, habituation would be expected even if food or water were presented independently of responding. The term reinforcer is used to distinguish these stimuli from other stimuli that are also present during operant situations (discriminative stimuli, the experimental enclosure, etc.).

2. Palya and Walter (1997) failed to find large within-session changes in responding in their Experiment 1. The use of schedules and methods of data analysis that differed substantially from ours may have contributed to their failure. One procedural difference is probably particularly important. Within-session changes in responding occur over absolute, not relative, time (McSweeney, 1992; McSweeney, Roll, \& Cannon, 1994; McSweeney, Weatherly, \& Swindell, 1995). That is, for example, the within-session pattern of responding found in a 20 -min session resembles the within-session pattern found during the first 20 min of a 60-min session. Sessions in Experiment 1 of Palya and Walter were as short as $4 \mathrm{~min}$ when subjects responded for high rates of reinforcement. Only small changes in responding would be expected over such short time periods. Although sessions were as long as $100 \mathrm{~min}$ for lower rates of reinforcement, within-session changes in responding are rarely found when subjects respond at low rates of reinforcement (McSweeney, 1992; McSweeney, Roll, \& Cannon, 1994).

3. Dishabituation is often produced, as was done here, by changing the nature of the presented stimulus rather than by adding a new stimulus (e.g., a loud tone, Vinogradova, 1970). However, this creates confusion because changing the presented stimulus also tests for stimulus specificity, a different characteristic of habituated behavior. If responding changes when the presented stimulus is altered, then habituation was also specific to the presented stimulus. The usual solution to this problem is to label a change in responding "dishabituation" if it is a change in the way that subjects respond after the original reinforcer is reintroduced. The change in responding is a violation of stimulus specificity if responding changes to the new stimulus when the original stimulus is not reintroduced. In that case, the change in responding indicates only that subjects respond differently to the new, than to the old, stimulus.

\section{APPENDLX}

The way in which within-session patterns of responding are represented may alter conclusions about whether a manipulation does or does not alter them. In most of our work, conclusions are based on an examination of the within-session patterns expressed by both absolute (response rates) and normalized (percentages or proportions of total-session responses) measures. That is, we usually plot the data in terms of proportions or percentages of total-session responses so that the reader can visually determine the form of the pattern. We also provide enough information to allow the calculation of absolute re-
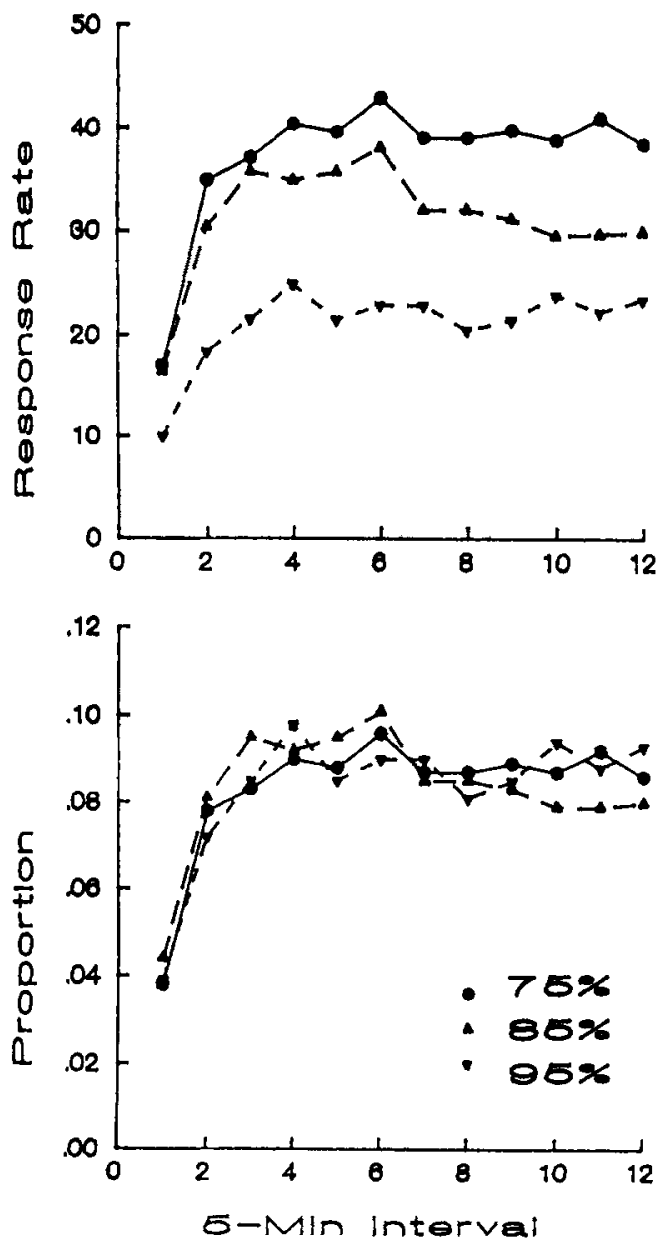

Figure A1. Rate of responding (responses per minute, top graph) and proportion of total-session responses (bottom graph) during successive 5-min intervals in the session for subjects maintained at $75 \%, 85 \%$, or $95 \%$ of their free-feeding body weights. Results were averaged over all subjects responding during the last five sessions for which a condition was conducted. NoteFrom "Satiety Contributes Little to Within-Session Decreases in Responding," by J. M. Roll, F. K. MeSweeney, K. S. Johnson, \& J. N. Weatherly, 1995, Learning \& Motivation, 26, p. 331. Copyright 1995 by Academic Press. Adapted with permission. 

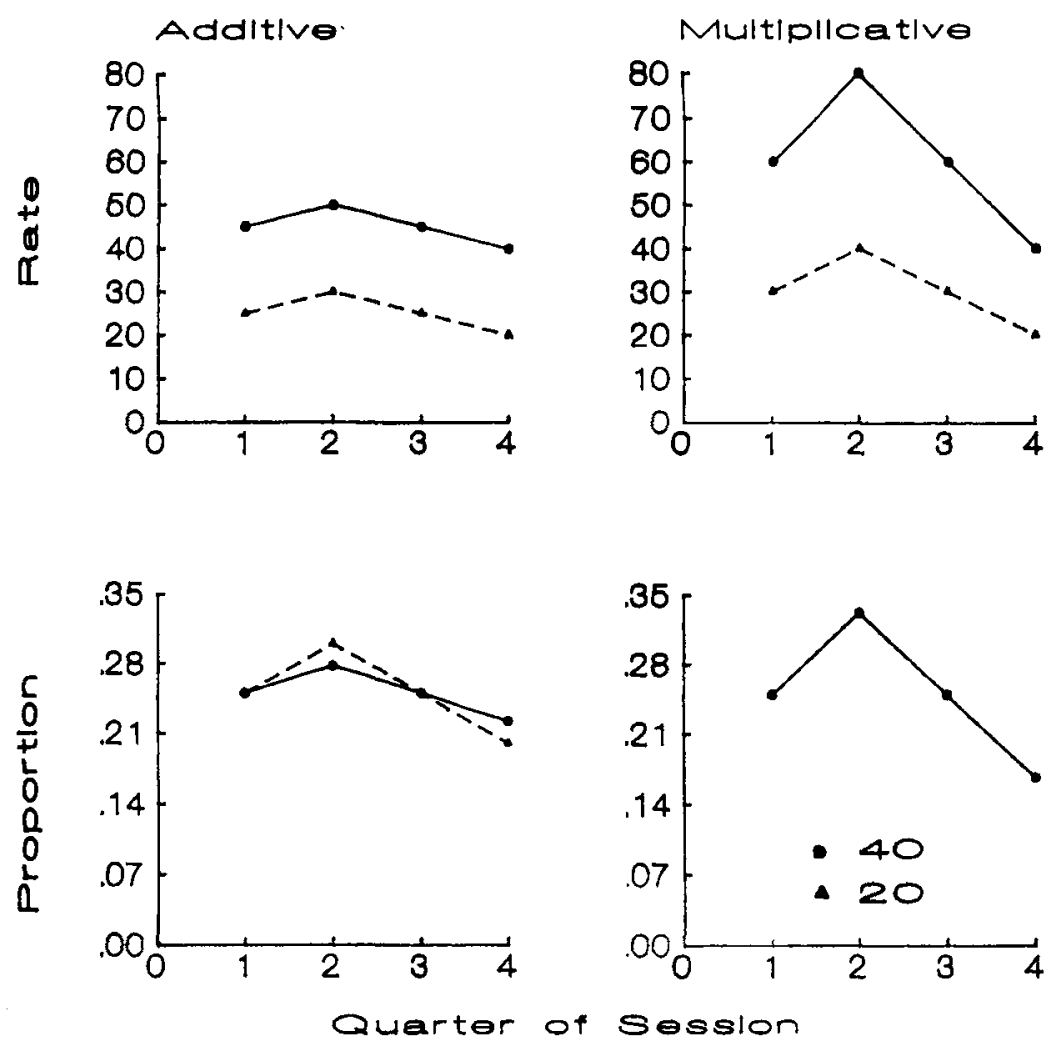

Figure A2. The top graphs present hypothetical response rates, calculated by making additive (left graph) or multiplicative (right graph) assumptions about how the factors that determine the within-session pattern of responding interact with the factors that determine absolute response rate. The bottom graphs show these absolute response rates transformed into proportions of total-session responses.

sponse rates and we usually apply our statistical tests to absolute, rather than to normalized, response rates to avoid violating assumptions.

We present normalized, as well as absolute, response rates because many data indicate that the factors that produce the within-session patterns of responding differ from the factors that govern absolute response rates. Large differences in absolute response rates may occur even when the within-session patterns of responding do not differ, and within-session patterns may differ when absolute response rates do not. Figure Al illustrates this point. It presents the rate of responding (top graph) and the proportion of total-session responses (bottom graph) during successive 5 -min intervals in the session for subjects maintained at $75 \%, 85 \%$, or $95 \%$ of their free-feeding body weights. Figure A1 shows that altering deprivation produces large changes in the absolute rates of responding (top graph) without altering the within-session changes in responding (bottom graph). As a result, we believe that the use of normalized response rates reveals the within-session pattern of responding uncontaminated by differences in absolute response rates.

It might be objected that normalized response rates distort the conclusions that would be drawn from absolute rates. Figure A2 shows that this is an oversimplification. It confirms that the use of absolute and normalized response rates can lead to different conclusions. But it also shows that the use of normal- ized rates may reveal or obscure the order in the data under different circumstances.

The top graphs in Figure A2 present hypothetical response rates, calculated by making additive (left graph) or multiplicative (right graph) assumptions about how the factors that determine the within-session pattern of responding interact with the factors that determine absolute response rates. Response rates in the left graph were calculated by adding $5,10,5$, and 0 responses per minute during successive quarters of the session to arbitrarily selected baseline response rates of 20 or 40 responses per minute. Response rates in the right graph were calculated by multiplying the baseline rates by $1.5,2.0,1.5$, and 1.0 during successive quarters of the session. The bottom graphs illustrate the effect of transforming absolute response rates into proportions.

The left graph shows that the transformation into proportions obscures the order in the data if the interactions are additive. That is, the similar within-session changes in absolute response rates become different when the rates are converted to proportions. This distortion is not large and it would be even smaller if proportions were calculated over the 12 within-session intervals that we use in most of our experiments. Nevertheless, the distortion is real. In contrast, the right graph shows that the transformation to proportions reveals the order in the data if the interactions are multiplicative. Different patterns of absolute re- 

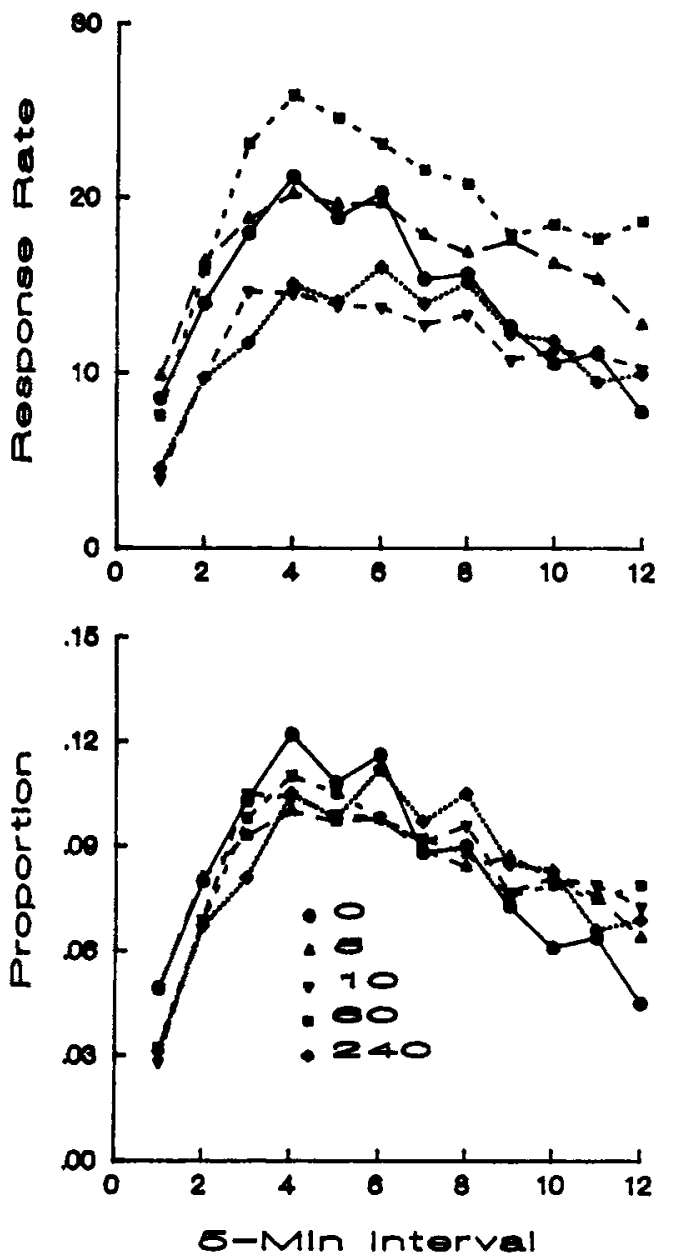

Figure A3. Rates of leverpressing (top graph) and proportion of total-session responses (bottom graph) during successive 5-min intervals (components) in the session. Each function presents the results for the mean of all subjects responding when a postsession feeding was delayed for $0,5,10,60$, or $240 \mathrm{~min}$ after the session. Note-From "Within-Session Responding as a Function of PostSession Feedings," by F. K. McSweeney, J. Hatfield, \& T. M. Allen, 1990, Behuvioural Processes, 22, p. 180 . Copyright 1990 by Elsevier Science-NL, Inc. Adapted with permission. sponse rates become identical when they are transformed to proportions. Because the patterns are identical, different functions for the 20 and 40 baselines are not visible in the lower right graph.

Many data from our laboratory indicate that normalized response rates reveal rather than obscure the order in the data. Figure A3 provides an example. The top graph presents rates of leverpressing during successive 5-min intervals in the session, as reported by McSweeney, Hatfield, and Allen (1990). Each function presents the results for the mean of all subjects responding when a postsession feeding was delayed for $0,5,10$, 60 , or $240 \mathrm{~min}$ after the session. The bottom graph presents the same results when they are transformed to proportions of totalsession responses. It is difficult to tell whether the within-session patterns of responding are similar for all delays to postsession feedings when absolute rates are examined. In contrast, the proportions presented in the bottom graph remove all doubt. The normalized within-session patterns of responding are strikingly similar at all delays to postsession feedings.

Our research on the generalized matching law (GML; e.g., Baum, 1974) also suggests that the factors that determine the within-session patterns of responding interact multiplicatively with the factors that determine absolute response rates. Our research shows that the fit and parameters of the GML do not change systematically within sessions when subjects respond on many concurrent schedules (see, e.g., McSweeney, Weatherly, $\&$ Roll, 1995). The fit and parameters change only if the components of the concurrent schedule provide qualitatively different reinforcers (McSweeney, Swindell, \& Weatherly, 1996c). Finding that the parameters of the GML do not usually change systematically within sessions is consistent with the idea that within-session changes in responding are produced by a factor that multiplies the effect of the factors that control absolute response rates. A multiplicative variable would cancel when the ratios of response rates are calculated to fit the GML.

To summarize, we believe that normalized response rates reveal rather than obscure the order in the data. However, our conclusions do not require that this argument be accepted. In this paper, we have discussed only cases in which absolute and normalized response rates support similar conclusions.

(Manuscript received July 28, 1997; revision accepted for publication November 10, 1997.) 